Amino acid metabolism enzymic defects

glycine

hyperglycinemia ketosis mental retardation methionine

\title{
Nonketotic Hyperglycinemia: An in vitro Study of the Glycine-serine Conversion in Liver of Three Patients and the Effect of Dietary Methionine
}

\author{
C.J. de Groot, J.A.Troelstra and F.A. Hommes ${ }^{[32]}$ \\ Department of Pediatrics, University of Groningen, School of Medicine, Groningen, The Netherlands
}

\begin{abstract}
Extract
Liver biopsies were performed on three patients suffering from the nonketotic form of hyperglycinemia. Direct assay of the enzymes involved in glycine-serine conversion revealed that the enzymic defect underlying this disease was due to nonfunction or absence of a glycine cleavage system. This enzyme system catalyzes the conversion of glycine to hydroxymethyltetrahydrofolic acid, carbon dioxide, and ammonia. In patients with hyperglycinemia, serine to glycine conversion is normal and patients depend on this metabolic conversion for their supply of $\mathrm{C}_{1}$ units. As glycine formed in this reaction cannot participate as a $\mathrm{C}_{1}$-unit donor, it cannot be metabolized further and consequently will accumulate.

A therapeutic approach was devised to supply the organism with sufficient $\mathrm{C}_{1}$ units and was achieved by addition of methionine to a diet devoid of serine and glycine.

As a consequence, the patient with hyperglycinemia does not rely so heavily on the glycine-serine conversion to fulfill his requirements for $\mathrm{C}_{1}$ units and glycine will not accumulate. Levels of glycine in plasma fell to normal values after feeding a diet with $0.3 \mathrm{~g}$ methionine $/ \mathrm{kg} / 24 \mathrm{~h}$ for a period of 10 days. It was demonstrated that the decrease in plasma glycine by administration of methionine was not due to increased excretion of glycine in the urine.
\end{abstract}

\section{Speculation}

These studies have yielded evidence that the nonketotic form of hyperglycinemia is due to absence or nonfunction of the enzymic system responsible for the conversion of glycine to $\mathrm{CO}_{2}, \mathrm{NH}_{3}$, and hydroxymethyltetrahydrofolic acid. To meet the requirements of the organism for $\mathrm{C}_{1}$ units the conversion of serine to glycine proceeds at an accelerated rate. This can be compensated by addition of methionine to the diet, which serves as an alternate $\mathrm{C}_{1}$-unit donor. Patients with hyperglycinemia that do not respond to serine- and glycine-free diets may respond to diets rich in methionine.

Introduction

Hyperglycinemia is an inborn error of amino acid metabolism characterized by high levels of glycine in blood and urine. Two forms of this disease are known: a ketotic and a nonketotic form. Both forms of hyperglycinemia are associated with mental retardation.

It is not clear whether the ketotic form of hyperglycinemia can be ascribed to a single enzymatic defect. Hyperglycinemia is also seen in some cases of 
methylmalonic acidemia and propionic acidemia [12].

Curlos et al. [6] described the first patient suffering from the ketotic form, while GeRritsen et al. [9] described a new form of idiopathic hyperglycinemia associated with hypoxaluria. Eleven patients suffering from the nonketotic form have since been described $[5,9,13,14,17,18,24,26]$.

The enzymatic defect of this disease is unknown. The patient described by GerRrTsen et al. [9] showed a decreased excretion of oxalic acid, which has been interpreted to result from a defect in the glycine oxidase system, an interpretation that has since been criticized [17] because the glycine oxidase system constitutes a physiological but minor pathway of glycine catabolism. An ingenious approach in elucidating the enzymatic defect of the disease has been applied by $\mathrm{Ny}$ HAN et al. [16] and by ANDo et al. [1]. They measured the rate of conversion of glycine to serine and carbon dioxide after injecting intravenously glycine labeled with ${ }^{14} \mathrm{C}$ in the 1 or 2 position. The authors postulated a defect in the oxidation of carbon 1 of glycine to $\mathrm{CO}_{2}$ and a defect in the conversion of carbon 2 of glycine to carbon 3 of serine. This is consistent with nonfunction of reaction $l$ in the following scheme:

$$
\begin{aligned}
& \mathrm{CH}_{2} \mathrm{NH}_{2}+\mathrm{NAD}+\mathrm{FH}_{4}+\mathrm{H}_{2} \mathrm{O} \Rightarrow \mathrm{CO}_{2}+\mathrm{NH}_{3}+\text { 1) } \\
& \mathrm{COOH}
\end{aligned}
$$$$
\text { glycine }
$$

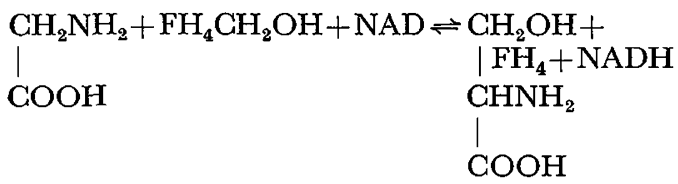

glycine serine

where: $\mathrm{FH}_{4}$ and $\mathrm{FH}_{4} \mathrm{CH}_{2} \mathrm{OH}$ represent tetrahydrofolic and hydroxymethyltetrahydrofolic acid, respectively.

Further information concerning the enzymic basis of this disease can be obtained by direct measurement of the rates of these reactions in a liver biopsy specimen. A liver homogenate was incubated under anaerobic conditions with ${ }^{14} \mathrm{C}-1$-glycine and ${ }^{14} \mathrm{C}-2$-glycine. This communication describes the results of these two determinations.

The suggestion of ANDo et al. [1] on the enzymic defect in the nonketotic form of hyperglycinemia could be confirmed.

\section{Patients}

Three patients, suffering from the nonketotic form of hyperglycinemia were studied [31]. Two of the pa- tients were described earlier [13]. All patients had been on the diet described by Jonxis [13] for more than 1 year.

Patient $\mathcal{F W}$ was the first child of healthy parents, who were second cousins. She was born weighing 2,600g after an 8 month pregnancy. At the age of 6 weeks, convulsions were observed; the EEG showed the typical pattern of hypsarrhythmia, for which she was treated with ACTH, without success. At the age of 11.5 months she came under our care because of a hyperglycinuria. At that time she was somnolent and grossly mentally retarded. Physical examination revealed no abnormalities. Routine laboratory values were within normal ranges. No acidosis was discovered, oxalic acid excretion was normal; however, paper electrophoresis of urine revealed a marked increase in excretion of glycine. Glycine concentration in plasma was $1.20 \mu \mathrm{moles} / \mathrm{ml}$ (normal range: $0.30-0.50 \mu \mathrm{mole} /$ $\mathrm{ml}$ ) other plasma amino acids were within the normal range. The diagnosis of hyperglycinemia was apparent and the patient was put on a synthetic diet free of serine and glycine [16]. The composition of this diet is given in DE GROOT et al. [8] and JonXIs [13].

After institution of the diet the level of glycine in the plasma decreased to the upper range of normal.

Patient EW is the younger sister of patient $\mathcal{F W}$. She was admitted to the hospital because of the family history. She was born after an uncomplicated pregnancy with a birth weight of $3,700 \mathrm{~g}$. During the first 4 days of life she was put on humanized milk ( $1 \mathrm{~g}$ of protein/kg body weight). She nursed poorly and convulsions were noted. At $72 \mathrm{~h}$ the level of glycine in plasma was found to be $1.1 \mu \mathrm{moles} / \mathrm{ml}$; other chemical studies of blood were within normal levels. There was no acidosis. A synthetic diet [13] was instituted and in the course of 14 days the plasma glycine levels decreased to $0.44 \mu \mathrm{mole} / \mathrm{ml}$. Thereafter the gain in weight and length was normal. She was, however, mentally retarded.

Patient TK was the second child of unrelated healthy parents; their other child was normal. She was admitted to the hospital at the age of 12 months because of severe mental retardation. At admission the child was lethargic, hypotonic, and mentally retarded. Physical examination revealed no other abnormalities. Chemical studies of blood were within normal limits. Paper electrophoresis of urine revealed a marked increase in excretion of glycine. The plasma glycine concentration was found to be $1.13 \mu \mathrm{moles} / \mathrm{ml}$; other amino acids were within the normal range. There was no acidosis. A synthetic diet [13] was instituted. Contrary to results obtained in patients $\mathcal{F W}$ and $E W$ the plasma glycine levels of patient $T K$ failed to descend to normal levels after institution of the diet and remained at a high level of 1.0-1.2 $\mu \mathrm{moles} / \mathrm{ml}$. 
A full description of these patients, their treatment and development will be given elsewhere.

\section{Methods}

Liver biopsies were taken with a Menghini needle under local anesthesia in the fasted patients.

The rate of conversion of glycine to serine in liver homogenates was assayed as described below. The assay mixture consisted of $1 \mathrm{ml} 0.05 \mathrm{M}$ potassium phosphate buffer, $\mathrm{pH} 7.5$, containing $90 \mu \mathrm{M}$ glycine, 0.5 $\mathrm{mm}$ formaldehyde, $50 \mu \mathrm{M}$ pyridoxalphosphate [3], $70 \mu \mathrm{m}$ nicotinamide adenine dinucleotide and $1.3 \mathrm{~mm}$ tetrahydrofolic acid [27].

Trial experiments with rat liver homogenate have indicated that this mixture yielded optimal results for measurement of the conversion of glycine into serine. To this mixture was added $1 \mu \mathrm{Ci}$ of carrier free ${ }^{14} \mathrm{C}-1$ glycine or ${ }^{14} \mathrm{C}-2$-glycine [28]. The liver biopsy, approximately $10 \mathrm{mg}$ in weight, was immediately homogenized in $0.2 \mathrm{ml}$ ice-cold $0.05 \mathrm{~mm}$ potassium phosphate buffer, pH 7.5, in a Potter-Elvejhem homogenizer. One-half of the homogenate was incubated with ${ }^{14} \mathrm{C}-1$ glycine in the assay medium; the other portion with ${ }^{14} \mathrm{C}$-2-glycine. After $1 \mathrm{~h}$ of incubation at $37^{\circ}$ under anaerobic conditions, $1.2 \mathrm{ml} \mathrm{20 \%} \mathrm{trichloroacetetic} \mathrm{acid}$ were added. The mixture was centrifuged for $10 \mathrm{~min}$ at $2,000 \times g$ and the precipitate discarded. A $20-\mu 1$ aliquot of the supernatant was subjected to high voltage paper electrophoresis at $\mathrm{pH} 1.8$ to separate glycine from serine [7]. A nonradioactive mixture of glycine and serine was run in parallel and developed with ninhydrin. The sections containing labeled glycine and serine were cut out, divided into small pieces ( $2 \mathrm{~mm}$ by $2 \mathrm{~mm}$ ), layered with $10 \mathrm{ml}$ of Bray's solution [4], and counted in a scintillation spectrometer. Amino acids in plasma and urine were measured quantitatively using an automatic amino acid analyzer $[15,29]$; plasma clearance was determined by the ${ }^{131}$ I-iothalamate method [21].

\section{Results}

The rates of incorporation of ${ }^{14} \mathrm{G}$ from ${ }^{14} \mathrm{G}$-1-glycine and ${ }^{14} \mathrm{C}$-2-glycine into serine by liver homogenates are shown in table $\mathrm{I}$. The rate of incorporation of labeled carbon atoms into serine from ${ }^{14} \mathrm{C}$-1-glycine was about equal to the rate of incorporation from ${ }^{14} \mathrm{C}$-2-glycine. This finding agrees with the results reported by NYHAN et al. [16] and ANDo et al. [1] when they administered glycine labeled in the 1 and 2 position to their patients. Recently STERN [23] and ScotT et al. [19], using the identical experimental approach of NYHAN and ANDO have reported the failure of a hyperglycinemic patient (nonketotic form) to incorporate the $\mathrm{C}-2$ of ${ }^{14} \mathrm{C}-2$ glycine into the $\beta$-carbon atom of serine, a result also in agreement with that of NYHAN and ANDo.

If reaction 1, vide supra, is not functioning in hyperglycinemia, then glycine cannot donate C-2 to tetrahydrofolic acid, and therefore, label from ${ }^{14} \mathrm{C}$-2-glycine will not be incorporated into $\mathrm{C}$-2 2 of serine. When liver homogenates of hyperglycinemic patients are incubated with ${ }^{14} \mathrm{C}$-1-glycine and with ${ }^{14} \mathrm{C}$-2-glycine equal rates of incorporation into serine will then occur. Under normal conditions, when both enzymes are active, a value for this ratio higher than 1 , with a maximum of 2 , will be found $[1,16]$.

A control experiment, carried out under identical conditions with rat liver homogenates confirmed this (table I).

Recently Yosmida et al. [25] described experiments similar to those reported here. Their data also demonstrated an almost equal rate of incorporation of label from ${ }^{14} \mathrm{C}$-1-glycine and from ${ }^{14} \mathrm{C}-2$-glycine into serine in the liver of a hyperglycinemic patient, while a control experiment with human liver from a normal subject yielded a ratio considerably higher than 1 .

In our three patients suffering from the nonketotic form of hyperglycinemia, the glycine cleavage system was absent or not functioning in the liver, as shown above; therefore, it appears likely that the enzymic defect underlying this inborn error is located in the glycine cleavage system. This finding poses a question on the therapeutic approach for patients with hyperglycinemia. The main function of reactions 1 and 2 is to supply the organism with $\mathrm{C}_{1}$ units, necessary for synthetic reactions. Specifically, glycine has a central position in $\mathrm{C}_{1}$ unit metabolism as donor for $\mathrm{C}_{1}$ units. It is this function of glycine that is blocked in hyperglycinemia. The metabolic need for $\mathrm{C}_{\mathrm{y}}$ units depends in this condition to a larger extent on reaction 2 . The result of

Table I. Rates of incorporation by liver of hyperglycinemic patients and of the rat of ${ }^{14} \mathrm{C}$ of ${ }^{14} \mathrm{C}$-I-glycine and ${ }^{14} \mathrm{C}$-2-glycine into serine

\begin{tabular}{|c|c|c|c|}
\hline Subjects & $\begin{array}{l}\text { Rate of in- } \\
\text { corporation } \\
\text { from }{ }^{14} \mathrm{C}-1- \\
\text { glycine, dpm/ } \\
\text { h/mg wet wt } \\
\text { of liver }\end{array}$ & $\begin{array}{l}\text { Rate of in- } \\
\text { corporation } \\
\text { from }{ }^{14} \mathrm{C}-2- \\
\text { glycine, dpm/ } \\
\text { h/mg wet wt } \\
\text { of liver }\end{array}$ & $\begin{array}{l}\text { Ratio of } \\
\text { rates of in- } \\
\text { corpora- } \\
\text { tion: } \\
{ }^{14} \mathrm{C}-2 \text {-glycine } \\
{ }^{14} \mathrm{C}-1 \text {-glycine }\end{array}$ \\
\hline $7 W$ & 88,612 & 73,861 & 0.85 \\
\hline$E W$ & 93,759 & 101,991 & 1.09 \\
\hline$T K$ & 125,633 & 93,611 & 0.74 \\
\hline Rat & 78,362 & 125,379 & 1.60 \\
\hline
\end{tabular}


the enzymic block will be an increased conversion of serine, a nonessential amino acid that can be formed from glucose, to glycine, via reaction 2 . The glycine thus formed cannot be used as a further $\mathrm{C}_{1}$-unit donor and consequently accumulates.

In relation to treatment, it is reasonable to try to decrease the glycine pool by reducing the intake of serine and glycine. This will, however, have only a limited effect because glycine may be formed at an increased rate by the patient. Moreover, when this therapeutic measure succeeds in reducing the glycine level in blood, this may cause a decreased availability of $\mathrm{C}_{1}$ units. Therefore, one might improve this treatment by supplying an alternative $\mathrm{C}_{1}$-unit donor with the diet. Methionine is then the amino acid of choice.

Addition of methionine to the diet may have two advantages : to donate $\mathrm{C}_{1}$ units, and to reduce the conversion of serine to glycine.

In our patient ( $T K$ ) a diet devoid of serine and glycine did not reduce the glycine levels and we attempted to decrease the level of glycine in plasma by administering methionine.

In figure 1, data from this trial are shown. When this patient received an increased amount of methionine, along with the synthetic diet [13], the glycine level in plasma dropped to normal values within a period of 10 days. During this methionine-loading period, cystine was omitted from the diet to keep the sulfur intake within known limits. Upon return to her

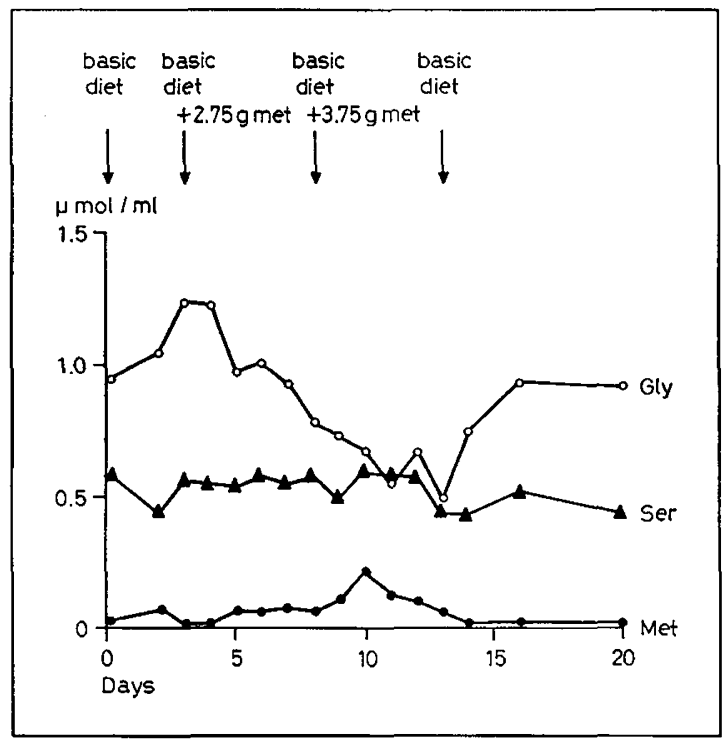

Fig. 1. Concentration of glycine, methionine, and serine in plasma of patient $T K$, before, during, and after addition of a 10 -fold amount of methionine to the basic diet. normal basic diet, glycine levels increased to pathologic values (fig. 1). The levels of serine in plasma did not change during methionine loading, and the levels of methionine remained within normal limits.

Scriver and Wilson [20] demonstrated that methionine is a strong competitive inhibitor of glycine uptake in rat kidney cortex slices; a $K_{\mathrm{s}}$ value of $6.9 \mathrm{~mm}$ for glycine was found and a $K_{\mathrm{i}}$ value of $0.6 \mathrm{~mm}$ for methionine was observed. The effect of methionine on tubular reabsorption, especially of glycine, was therefore investigated to determine whether the decrease in plasma glycine during a methionine load was indeed due to a metabolic effect as outlined above, or could be ascribed to an increased excretion of glycine with the urine. Despite the fact that intravenous administration of methionine raised the methionine level in plasma considerably above normal, tubular reabsorption of amino acids was not significantly changed. There was no change in tubular reabsorption in any amino acid except for aspartic acid, which fell from 68.8 to $35 \%$ during loading, and for glycine, which rose from 84.6 to $91.3 \%$ reabsorption. This was confirmed when methionine was administered orally. There is, therefore, no reason to suppose that the decrease in level of plasma glycine by administration of methionine was due to increased excretion of glycine in the urine.

\section{Discussion}

The results obtained in these three patients provide evidence that the enzymic defect underlying the nonketotic form of hyperglycinemia is due to absence or nonfunction of the glycine cleavage system catalyzing reaction 1 (Introduction).

The equal rates of incorporation of ${ }^{14} \mathrm{C}-1$-glycine and ${ }^{14} \mathrm{C}-2$-glycine into serine by liver homogenates of hyperglycinemic patients that were observed were consistent with the suggestion by NYHAN et al. [16] and by ANDo et al. [1] regarding the enzymic defect of this disease. The rates of incorporation of label into serine from glycine, labeled in the 1 and 2 position, were rather high, especially if compared with those reported by Yosmida et al. [25]; however, it should be pointed out that the conditions for the assay of these rates were such that maximal rates could be observed. It was found that addition of NAD, pyridoxalphosphate, formaldehyde, and tetrahydrofolic acid were necessary to obtain maximal rates. Furthermore, anaerobic conditions enhanced the rate of conversion of glycine to serine. Yoshida et al. [25] carried their assays out under aerobic conditions and did not add the above mentioned coenzymes.

With the present knowledge of the enzymatic defect it may be possible to improve the dietary treatment. 
As the enzyme that is missing or nonfunctioning in this disease has a central position in the supply of $\mathrm{C}_{1}$ units, which are necessary for synthetic reactions, any therapeutic approach should take into account the necessity for a different route of supply of $\mathrm{C}_{1}$ units. By providing the organism with sufficient $C_{1}$ units, the reliance on the serine-glycine conversion to obtain $\mathrm{C}_{1}$ units is obviated, and consequently, glycine will not accumulate. This set of conditions is achieved by administration of methionine; this amino acid donates a terminal methyl group when the amino acid is metabolized to cysteine.

The methyl group of methionine is primarily involved in transmethylation reactions. The conversion of serine to choline makes use of such transmethylation reactions. The degradative breakdown of choline proceeds, however, partly via tetrahydrofolate-dependent reactions. In this way, an indirect link between transmethylation reactions and the reactions of $\mathrm{C}_{1}$ unit metabolism involving tetrahydrofolate is possible.

We did not consider the use of choline as a preferred alternate $\mathrm{C}_{1}$-unit donor because for every three $\mathrm{C}_{1}$ units donated, one glycine molecule remains. The amino acid, histidine, may be used as a replacement for methionine; however, this amino acid is a less effective $\mathrm{C}_{1}$-unit donor than methionine. Furthermore, the occurrence of the inborn error, hyperhistidinemia [10], also associated with mental retardation, suggests the need for caution when raising the plasma levels of histidine above normal, despite the observation that perhaps half of the patients with this disorder have no clinical manifestations. Figure 1 shows that administration of methionine does indeed lower the level of glycine in plasma.

The observation that the response of plasma glycine was only unambiguous 6 days after methionine administration may be related to a restricted permeability of glycine across cell membranes as seen in chick embryo heart [11] and rat brain slices [2].

A mutual relation between glycine and methionine in plasma is also evident from the work of SNYDERMAN et al. [22], who found that after a high protein intake $(9 \mathrm{~g}$ protein $/ \mathrm{kg} / 24 \mathrm{~h}$ ) plasma levels of methionine increased and those of glycine decreased.

The studies on the tubular reabsorption of amino acids, with and without administration of methionine, have yielded evidence that the decrease in plasma glycine is not due to an increased excretion of glycine.

Scriver and WiLson [20] have shown that in rat kidney cortex slices methionine inhibits the uptake of glycine. The plasma methionine concentrations achieved by us, however, are much lower than 0.6 $\mathrm{mm}$ (a $K_{\mathrm{i}}$ value for methionine of $0.6 \mathrm{~mm}$ was observed, i.e., at $0.6 \mathrm{~mm}$ methionine half maximum inhibition of glycine uptake can be observed).
Two of the patients described here, $\mathcal{F W}$ and $E W$, have reacted favorably to the synthetic diet free of serine and glycine, as far as levels of glycine in plasma are concerned. Similar results were not obtained in patient $T K$, notwithstanding all three patients were clinically similar and all demonstrated the same enzyme defect. Judged by the reaction to dietary treatment, two forms of the nonketotic form of hyperglycinemia may be distinguished.

It has been reported [16] that addition of certain amino acids, leucine, isoleucine, threonine, valine, and methionine, to the diet can produce ketosis in patients with hyperglycinemia of the ketotic type. It should be mentioned that no signs of ketosis were observed in our patients receiving extra doses of methionine. Furthermore, no periods of ketosis were reported in our patients prior to institution of the synthetic diet.

The observation that administration of methionine decreases the plasma levels of glycine without increasing excretion of glycine in the urine is in agreement with the postulated enzymic defect in hyperglycinemia. It indicates that with administration of an alternate $\mathrm{C}_{1}$ unit donor (methionine) the hyperglycinemic patient does not rely so heavily on serine-glycine conversion to meet its $\mathrm{C}_{1}$ unit requirement and, therefore, glycine does not accumulate. Whether long-term treatment with methionine will clinically improve the patient's condition, remains to be determined in future evalua. tions.

\section{Summary}

Glycine-serine conversion was studied in liver biopsies of three patients suffering from the nonketotic form of hyperglycinemia. The enzymic defect in this disease could be ascribed to nonfunction of the glycine cleavage system. Levels of glycine in plasma in hyperglycinemic patients can be lowered by administration of high doses of methionine. It could be demonstrated that the decreased levels of glycine in plasma that occurred were not due to elevated excretion of glycine in the urine but rather to different routes of supply of $\mathrm{C}_{1}$ units other than the conversion of serine to glycine; methionine thus serves as a $\mathrm{C}_{1}$-unit donor.

\section{References and Notes}

1. Ando, T.; Nyhan, W.L.; Gerritsen, T.; Gang, L.; Heiner, D. C. and Bray, P.F.: Metabolism of glycine in the nonketotic form of hyperglycinemia. Pediat. Res. 2: 254 (1968).

2. BARbosa, E.; JoAnny, P. and Corriol, J.: Uptake of some amino acids by rat brain slices: effect of various substrates. Experientia 24: 1196 (1968). 
3. BRAKLEY, R.L.: The interconversion of serine and glycine; participation of pyridoxyl phosphate. Biochem.J. 61: 315 (1955).

4. BRAY, G.A.: A simple efficient liquid scintillator for counting aqueous solutions in a liquid scintillation counter. Analyt. Biochem. 1: 279 (1960).

5. Garson, N.A.J.: Biochemical surveys of mental handicap; in: J.D. AllaN and K.S.Holt: Biochemical approaches to mental handicap in childhood, p. 3 (Livingstone Ltd., London 1965).

6. Ghilds, B.; Nyhan, W. L.; Borden, M. ; Bard, L. and Cooke, R. E.: Idiopathic hyperglycinemia and hyperglycinuria: A new disorder of amino acid metabolism. Pediatrics 27: 522 (1961).

7. Glotten, R. and Clotten, A.: HochspannungsElektrophorese (Thieme, Stuttgart 1962).

8. De Groot, C.J.; Hommes, F.A. and Jonxis, J.H.P.: in: Symp. on Phenylketonuria (Springer, Heidelberg 1969) (in press).

9. Gerritsen, T.; Kaneggia, W. and Waisman, H.A.: A new type of idiopathic hyperglycinemia with hypo-oxaluria. Pediatrics 36: 992 (1965).

10. Ghadimi, H.; Partington, M.W. and Hunter, A.: A familial disturbance of histidine metabolism. New Engl.J. Med. 265: 221 (1961).

11. Guidotti, G. G.; Gaja, G.; Loreti, L.; Ragnotti, G.; RottenberG, D.A. and Borghetti, A.F.: Amino acid uptake in the developing chick embryo heart. Biochem.J. 107: 575 (1968).

12. Hsia, Y.E.; Scully, K.J. and Rosenberg, L.E.: Defective propionate carboxylation in ketotic hyperglycinaemia. Lancet $i: 757$ (1969).

13. Jonxrs, J.H.P.: in: Brain damage by inborn errors of metabolism, p. 9 (F.Bohn, Haarlem 1968).

14. MABRY, G. G. and KARAM, A.: Idiopathic hyperglycinemia and hyperglycinuria, Sth.med.J. 56: 1444 (1963).

15. Moore, S. and Stein, W.H.: A modified ninhydrin reagent for the photometric determination of amino acids and related compounds. J.biol. Chem. 211: 907 (1954).

16. Nyman, W.L.; Ando, T. and Gerritsen, T.: Hyperglycinaemia; in: W.L. NYHAN: Amino acid metabolism and genetic variation, p.255 (McGraw-Hill, New York 1967).

17. Rampin, S.; Visscher, D.; Curtius, H.S.; ANDERS, P.W.; TANGREdr, F.; FrISSGHKNEGHT, W. and Prader, A.: Heriditäre Hyperglicinämie. Helv. paediat. Acta 22: 135 (1967).

18. SchreIER, K.: Glycinoses and different glycinurias observed in Europe; in: W. L. NYHAN : Amino acid metabolism and genetic variance, p.273 (McGraw-Hill, New York 1967).

19. Sсотt, G.R.; Clark, S. and TenG, C.: Nonketotic hyperglycinemia: evidence for unidirectional defect in serine-glycine interconversion. Pediat. Res. 3: 356 (1969).

20. Scriver, G.R. and Wilson, O.H.: Possible locations for a common gene product in membrane transport of amino acids and glycine. Nature, Lond. 202: 92 (1964).

21. Srgman, E.M.; Elwood, C.M. and Knox, F.: The measurement of glomerular filtration rate in man with sodium iothalamate ${ }^{131}$ (Conray). J. nucl. Med. 7: 60 (1965).

22. Snyderman, S.E.; Holt, L.E.; Norton, P.E.; Roitman, E. and Phansalkar, S.V.: The plasma aminogram. I. Influence of the level of protein intake and a comparison of whole protein and amino acid diets. Pediat. Res. 2: 131 (1968).

23. Stern, J.: In: Symp. on phenylketonuria (Springer, Heidelberg 1969) (in press).

24. TADA, K.; Yoshida, T.; Morikawa, T.; MinaKaWA, A.; WadA, Y.; ANDo, T. and ShImura, K. : Idiopathic hyperglycinaemia (the first case in Japan). Tahaky J.Exp. Med. 80: 218 (1963).

25. Yoshida, T.; KIKUCKI, G.; TAdA, K.; Narisama, K. and Arakawa, T.: Physiological significance of glycine cleavage system in human liver as revealed by the study of a case of hyperglycinaemia. Biochem. biophys. Res. Commun. 35: 577 (1969).

26. Zirter, F.A.; Heiner, D. C.; Bray, P.F.; MaDSEN, J.A. and NYHAN, W.L.: The clinical findings in a patient with nonketotic hyperglycinemia. Pediat. Res. 2: 250 (1968).

27. Purchased from Sigma Chemical Company, St. Louis, MO; used without further purification.

28. Obtained from Radiochemical Gentre, Amersham, England.

29. Spinco model 120B, Beckman Instruments, Inc., Spinco Division, Palo Alto, California (USA).

30. Our thanks are due to Professor Dr. J.H.P.Jonxis for discussion and critical evaluation of the manuscript.

31. All procedures were performed in accordance with the provisions set forth in the Declaration of Helsinki.

32. Request for reprints should be addressed to: F.A. Hommes, Ph.D., Department of Pediatrics, State University, 59 Oostersingel, Groningen (The Netherlands).

33. Accepted for publication October 3, 1969. 